HARRAN ÜNIVERSITESI

MÜHENDISLIK DERGisi

HARRAN UNIVERSITY JOURNAL OF ENGINEERING

e-ISSN: 2528-8733

\section{HARRAN ÜNIVERSITESİ MÜHENDİSLİK DERGISİ}

HARRAN UNIVERSITY JOURNAL of ENGINEERING

e-ISSN: 2528-8733 (ONLINE)

URL: http://dergipark.gov.tr/humder

\title{
Geri Kazanılmış Agrega İkamesinin Kendiliğinden Yerleşen Betonların Bazı
} Sertleşmiş Özelliklerine Etkisi

The Effect of Recycled Aggregate Replacements on Some Hardened Properties of SelfCompacting Concrete

Yazar (Author): Zeynep ALGIN 1

1 ORCID ID: 0000-0001-7004-8403

Bu makaleye şu şekilde atıfta bulunabilirsiniz (To cite to this article): Algın Z., "Geri Kazanılmış Agrega İkamesinin Kendiliğinden Yerleșen Betonların Bazı Sertleșmiş Özelliklerine Etkisi", Harran Üniversitesi Mühendislik Dergisi, 5(3): 183-193, (2020).

Erișim linki (To link to this article): http://dergipark.gov.tr/humder/archive 


Mühendislik Dergisi

Araştırma Makalesi

\title{
Geri Kazanılmış Agrega İkamesinin Kendiliğinden Yerleşen Betonların Bazı Sertleşmiş Özelliklerine Etkisi
}

\author{
Zeynep ALGIN ${ }^{1, *}$ \\ ${ }^{1}$ Harran Üniversitesi, Mühendislik Fakültesi, İnşaat Mühendisliği Bölümü, 63100, Haliliye/ŞANLIURFA
}

\begin{abstract}
$\ddot{O} z$
Makale Bilgisi

Bașvuru: 23/10/2020

Yayin: 25/12/2020

Anahtar Kelimeler

Kendiliğinden yerleşen beton

Geri kazanılmışagrega

Basınç dayanımı

Geçirimlilik

Birçok çevresel ve ekonomik avantajlardan dolayı, geri kazanılmış beton agregalarının Kendiliğinden Yerleşen Beton (KYB) imalatında kullanımına yönelik, temel prensiplerin belirlenme ihtiyacı, bu agregaların hangi fraksiyonlarda ve miktarlarda, KYB'nin sertleşmiş özelliklerini nasıl etkilediği konusunun, araştırılması gereksinimini doğurmuştur. Bu amaçla, sunulan çalışma kapsamında, laboratuvar ortamında üretilen beton numuneler çeneli ve konik kırıcılardan geçirildikten sonra, iri ve ince Geri Kazanılmış Agrega (GKA) elde edilmiştir. Elde dilen GKA'lar, doğal iri agregayla \%0, 50 ve 100 oranında ikame edilerek ve her bir düzeyde doğal ince agregayla $\% 0,25,50,75$ ve 100 oranlarında yer değiştirilerek KYB üretimleri gerçekleştirilmiştir. Bu kapsamda 0.32 su/bağlayıcı oranına sahip 15 karışım tasarlanmış olup bu karışımlarda bağlayıcı miktarının \%20'si oranında uçucu kül kullanılmıştır. Bu değişken GKA ikame düzeylerinin KYB'lerin hızlı klor geçirimliliği, kılcal su geçirimliliği ve basınç dayanımı gibi bazı sertleşmiş özellikleri üzerindeki etkileri araştırılmıştır. GKA ikame düzeyindeki artışa bağlı olarak KYB'lerin basınç dayanımında azalma olduğu, bu fraksiyonlardaki değișimin KYB'lerin basınç dayanımını önemli bir oranda etkilediği, ince GKA ikame düzeyindeki artışın kılcal su emme değerlerinde artışa ve klorür iyon geçirimliliği direncinde düşüşe sebep olduğu görülmüştür.
\end{abstract}

Keywords

Self-compacting concrete Recycled aggregate

Compressive strength

Permeability

\section{The Effect of Recycled Aggregate Replacements on Some Hardened Properties of Self-Compacting Concrete}

\begin{abstract}
Owing to the several environmental and economic advantages, the necessity upon identifying the basic principles for the utilization of recycled concrete aggregates in the production of SelfCompacting Concrete (SCC) has brought about the need to investigate in which fractions and quantities these aggregates affect the hardened properties of SCC. For this purpose, within the scope of the presented study, the coarse and fine Recycled Concrete Aggregate (RCA) fractions were obtained from the concrete samples produced in the laboratory by processing through jaw and cone crushers. The SCC mixes were produced by replacing the natural coarse aggregate at the rate of 0,50 and $100 \%$ and the natural fine aggregate at the rate of $0,25,50,75$ and $100 \%$ in each level. Accordingly, 15 mixtures were designed; the water to binder ratio was kept constant as 0.32 and fly ash was used in the amount of $20 \%$ of the binder content. The effects of these variations in aggregate levels on some of the hardened properties of SCC such as rapid chloride permeability, sorptivity and compressive strength were investigated. It has been observed that, due to the increase in the RCA replacement level, the compressive strength of SCCs decreases, the variation in these fractions significantly affects the compressive strength of SCCs, the increase in the fine RCA replacement level causes a reduction in the sorptivity values and a decrease in chloride ion permeability resistance.
\end{abstract}

\section{GİRIŞ (INTRODUCTION)}

Yapı malzemelerinin sürdürülebilirliği ve üretim aşamalarındaki karbon salınım miktarı konularıyla alakalı sektörel endişeler nedeniyle beton üretiminde farklı atık türlerinin kullanımı giderek yaygınlaşmaktadır.

\footnotetext{
* Zeynep ALGIN, e-mail: zyilmaz@harran.edu.tr
} 
Belirli atıkların eklenmesiyle üretilen vibrasyonlu betonun optimal davranışının geleneksel beton davranışına rakip olabileceği artık yaygın olarak kabul edilmektedir. Kendiliğinden yerleşen beton gibi özel betonların imalatı da bu kapsamda araştırılmakta olup yaygın kullanımlarıyla ilgili çalışmalar devam etmektedir. Kendiliğinden Yerleşen Beton (KYB), donatı sayısının fazla olduğu, dar ve derin kesitlere kendi ağırlığı ile kalıp içi veya dışı vibrasyon gerektirmeden, yerleşebilen akışkan özellikli bir beton çeşidi olup segragasyon ve terlemeye yol açmadan stabilitelerini koruyabilirler. KYB üretiminde geri kazanılmış agrega kullanımı ile alakalı olarak, mevcut literatürde sınırlı sayıda bilimsel araştırmalar bulunmaktadır. $\mathrm{Bu}$ tür bir kullanım, inşaat atıklarının olumsuz çevresel etkilerini azaltmasının yanında sınırlı olan doğal kaynakların tüketimini de kontrol etmeyi amaçlamaktadır.

İnşaat sektörüne atfedilen $\mathrm{CO}_{2}$ emisyonları ve muazzam doğal kaynak tüketimi, küresel düzeyde önemli çevresel endişelere yol açmaktadır [1]. Beton ve asfalt karışım malzeme üretimlerinde, geoteknik faaliyetler kapsamında dolgular, setler ve bazı baraj türlerinin inşasında, hidrolik su kanalları ve boru sistemlerinin yatakları gibi birçok mühendislik faaliyetinde kullanılan doğal agregaların üretilmesi aşamalarında büyük miktarlarda enerji tüketilmektedir [2]. Çimento fabrikalarındaki ve asfalt ve beton tesislerindeki üretim aşamalarında yüksek atmosferik $\mathrm{CO}_{2}$ emisyonu hususu beton üretimi açısından son zamanlarda tartışılmaktadır [3]. Beton dünyadaki atıkların önemli bir bölümünü oluşturmaktadır. Uzun ömürlü olmasına rağmen, insan gereksinimlerindeki değişime bağlı olarak kullanım ömrü değişebilmektedir. Beton sektöründe kullanılan en önemli hammaddelerden biri olan agrega, Avrupa'da yılda yaklaşık 7 ton, Türkiye'de kişi başına 4 ton civarında üretilmektedir. Agrega, dünya genelinde maden üretiminin\% $\%$ 58'i ile ilk sırada yer almaktadır [4]. KYB üretiminde Geri Kazanılmıs Agrega (GKA) kullanımı konusu yeni bir bilimsel çalışma alanı olup bu hususta sınırlı sayılabilecek bilimsel araştırmalar yapılmıştır (örneğin, [515]). Bu husus Algın [11] tarafından doktora araştırması kapsamında detaylı olarak incelenmiş ve bu sunulan yayında tartışılmıştır. Elde edilen sonuçlar hem bilimsel açıdan hem de pratik kullanım açısından oldukça önemlidir. GKA kullanılarak hazırlanan KYB'nin de normal KYB'nin taze özellikleri gibi EFNARC [16] sınırlamalarını karşılaması gerekmektedir.

Çeşitli miktarlarda iri GKA kullanılarak üretilmiş KYB'lerin bazı taze ve sertleşmiş özellikleri üzerinde yapılan çalışmalarda, GKA'ların yüksek su emme özelliklerinden dolayı karışımlara ilave su eklenmiştir [6]. Geri kazanılmış agreganın ikame seviyesi arttırıldığında, agregaların gözenekli iç yapısı nedeniyle betonun yoğunluğu azalmaktadır. Elde edilen azalma, \%50-100 aralığındaki iri GKA ikame seviyesi için yaklaşık olarak \%2-4 oranlarında olduğu ifade edilmiştir. Basınç dayanımının, kullanılan GKA'nın kalitesinden doğrudan etkilendiği görülmüştür. İyi bir iç yapıya sahip yüksek kalitede GKA kullanıldığında, basınç dayanımındaki düşüşün minimal düzeyde olduğu belirtilmiştir. Bazı araştırmalarda \%50-100 aralığındaki GKA ikame seviyesi için dayanımdaki azalışın \%3-9 oranları arasında olduğu ifade edilmiştir. Çekme dayanımındaki (eğilmede) azalmanın aynı ikame aralığı için \%2-14 düzeyleri arasında olduğu belirtilmiştir. Agregaların gözenekli iç yapısı nedeniyle, betonun su emme kapasitesinin kullanılan GKA miktarına bağlı olarak artma gösterdiği bilinmektedir. Aynı seviye aralığında kullanılan iri GKA ikame düzeyleri için bu artışın \%0.1-0.4 aralığında olduğu ifade edilmektedir. Su emme kapasitesi, GKA üzerine yapışmış kılcal gözenekli yapıdaki eski çimento harcı ile betonun yeni çimento harcı ile doğrudan ilişkilidir. Dolayısıyla yeni beton karışımı tasarlarken kullanılacak GKA'nın kaynağının bilinmesi önemli olmaktadır, zira yüksek kalitede beton gerekliyse GKA'nın üretildiği betonunun da yüksek kalitede olması uygun olacaktır.

Çeşitli miktarlarda kullanılan iri GKA'ların KYB'nin taze ve geçirgenlik özellikleri üzerindeki etkisi de daha önceki bazı çalışmalarda, yarı sabit su/çimento oranı ve kademeli olarak artırılan süper-akışkanlaştırıcı değişimlerine bağlı olarak araştııılmıştır [9]. Bu araştırmada GKA'lar kuru durumda kullanılmıştır. Sertleşmiş betonun yoğunlukları arasındaki karşılaştırmada, GKA'ların ikame seviyelerinin artırılması durumunda, küçük kütlesel bir kaybın elde edildiği görülmüştür. Basınç dayanımındaki azalışın \%100 ikame seviyesi için $\% 5$ olduğu vurgulanmıştır.

Çeşitli miktarlarda ince GKA kullanımının değişen su/bağlayıcı oranları ile hazırlanan KYB'nin bazı sertleşmiş ve taze özellikleri üzerine nasıl bir etki yaptığı önceki çalışmalarda araştırılmıştır [7]. GKA'lar genellikle daha yüksek su emme oranlarını temsil ettiklerinden, bu çalışmada karışımlara ilave su eklenmiş ve GKA'lar hava kurusu durumda kullanılmıştır [7]. GKA ve doğal agrega arasındaki yoğunluk farkından dolayı ince GKA düzeyinin artmasıyla KYB karışımlarının taze yoğunluk değerlerinin azaldığı ifade edilmiştir. $0.53 \mathrm{su} /$ bağlayıcı oranına sahip KYB karışımlarının 28 günlük basınç dayanımı değerlerinin, 
\%25-50 ince GKA ikame seviye aralığ için, önemli ölçüde değişmediği belirtilmiştir. Erken yaşlarda (1-7 gün) basınç dayanımı değerlerinin, ince GKA ikame seviyesinin \%50'den \%100'e yükseltilmesi durumunda az bir miktar düştüğü belirtilmiştir. Geç kür yaşlarındaki (28 ve 90 gün) basınç dayanımı değerlerinin ise, ince GKA ikame seviyesinin \%75'den \%100'e yükseltilmesi durumunda yaklaşı \%10 oranında azaldığ1 ifade edilmiştir. İnce GKA ikame seviyesinin \%25-50 aralığı için $0.44 \mathrm{su} /$ bağlayıcı oranıyla üretilmiş KYB karışımlarının 28 ve 90 günlük basınç dayanımı değerlerinin kontrol betonunkinden daha yüksek olduğu belirtilmiştir. İnce GKA ile hazırlanan KYB karışımlarının klorür iyon geçirimliliği değerlerinin, 0.53 su/bağlayıcı oranı için, orta veya düşük olarak sınıflandığı belirtilmiştir. İnce GKA içeriğinin artması, bu agreganın dolgu etkisine bağlı olarak klorür iyonu penetrasyon direncinde artışa sebep olduğu ifade edilerek, bunun kaynağı olarak doğal ince agregaya kıyasla ince GKA'nın daha yüksek düzeyde küçük partiküller içermesi gösterilmiştir. Panda ve Bal [8], yıkılmış 25 yıllık bir binadan elde ettiği iri GKA'larla ürettiği KYB'lerin test sonuçları ile geleneksel betondan elde ettiği sonuçları karşılaştırmıştır. KYB'lerin basınç dayanımı, eğilme dayanımı ve yarmada çekme dayanımı sonuçlarının, geleneksel betona göre daha düşük olduğu ve iri GKA ikame düzeyi arttıkça bu sonuçların azaldığı ifade edilmiştir. Hedeflenen 28 günlük basınç dayanımı değerlerine, \%30 iri GKA ikame düzeyli KYB karışımlarında ulaşıldığı belirtilmiştir.

Corinaldesi ve Moriconi [5], GKA ile üretilen KYB'ler üzerine testler yaparak, özellikle ince GKA fraksiyonunun doğal ince agrega yerine kullanılması durumunda, KYB'nin mekanik performansının düştüğünü belirtmiştir. Bununla birlikte, iri GKA kullanılması halinde, elde edilen 28 günlük basınç dayanımının, yapısal beton olarak tatmin edici performansta olduğu belirtilmiştir. Panda ve Bal [8], ve Pereira-De-Oliveira vd. [9], \%0-40 arasında değişen düzeylerdeki GKA ikame seviyeleri kullanarak, bu durumlarda basınç dayanımının azaldığını ifade etmişlerdir. Pereira-De-Oliveira vd. [9] dayanımda \%3 oranında bir düşüş olduğunu kaydederken, Panda ve Bal [8] referans KYB'ye kıyasla yalnızca \%75'lik bir basınç dayanımına ulaşıldığını ifade etmişlerdir. Basınç dayanımındaki azalma, yüksek su emme değerlerine sahip olan GKA'ların beton karışımın su/çimento oranını arttırmasıyla açıklanmıştır. Bununla birlikte, her iki çalışma arasındaki farkın sebebi olarak kullanılan GKA'ların köken farkı gösterilebilir. Manzi vd. [17] düşük GKA ikame düzeylerini araştırmış olup Fiol vd. [14], \%50-100 GKA ikame düzeylerinde üretilen betonları incelemiştir. Her iki çalışmada da GKA kullanılarak üretilen KYB'nin basınç dayanımı değerlerinin, doğal agrega ile üretilmiş KYB'den daha yüksek olduğu sonucuna varmışlardır (Her iki çalışmada da \%100 iri GKA kullanımı KYB'nin basınç dayanımını yaklaşık \%16 oranında arttırdığı ifade edilmiştir.) Yazarlar GKA'nın doğal agregaya kıyasla daha yüksek su emiliminin olduğunu belirterek, tüm karışımlara sabit su miktarının eklendiğini ve agregaların kuru durumda kullanıldığını belirtmişlerdir. Ayrıca, tüm bu faktörlerin daha düşük bir su/çimento oranı ürettiğini ve bunun da daha yüksek bir basınç dayanımının elde edilmesinde etkili olduğunu ifade etmişlerdir. Salesa vd. [18] su miktarının her aşamada aynı olması, hidrate olmamış harç içeriği artarken, daha fazla su emme miktarının oluşmasına ve daha yüksek basınç dayanımına yol açtığını ifade etmiştir.

Grdic vd. [6], ekstra GKA su emilimini telafi etmeyi ve çalış1lan farklı yüzdeler için (\%50 ve \%100 iri GKA oranları için) tek düzeyli bir su/çimento oranını korumayı amaçlamıştır. Karışımlar etkili bir su/çimento oranı ile tasarlandığında GKA içeriği arttıkça basınç dayanımında bir azalma gözlemlendiği belirtilmiştir. Assaad [19], sabit bir su/çimento oranında yüksek oranda iri GKA kullanarak daha düşük basınç dayanımlarına sahip KYB örnekleri elde etmiştir. Manzi vd. [17] tarafından yapılan çalışmada, karışıma düşük miktarlarda ince GKA dahil edilmesinin (\%20'nin altında) basınç dayanımı üzerinde kayda değer bir etkisinin olmadığı ifade edilmiştir. Campos vd. [20], \%20'lik bir ikame yüzdesiyle ince ve iri GKA kullanılarak elde edilen betonun basınç dayanımında yalnızca \%5'lik bir azalma olduğunu belirtmiştir. Bununla birlikte, aynı etki, Carro-Lopez vd. [21] tarafindan yapılan çalışmada daha yüksek ikamelerde daha belirgin bir durum oluşturmuş olup sabit bir su/çimento oranı için ince GKA'nın \%100 ikamesi basınç dayanımını yaklaşı \% 40 oranında düşürdüğü ifade edilmiştir.

Değerlendirilen literatür çalışmaları gösteriyor ki, kullanılan GKA'nın nem durumu ve karışıma sabit miktarda ek su katılması, KYB'nin özelliklerini önemli oranda etkilemektedir. Bu çalışmada ise farklı oranlarda ince ve iri GKA doygun yüzey kuru durumda kullanılarak KYB'nin özelliklerine etkisi araştırılmıştır. Sunulan çalışmada, ilk aşamada, laboratuvar ortamında üretilen beton numuneler iki aşamalı kırıcı sistemine tabi tutularak ince ve iri GKA'lar üretilmiştir. GKA'ların yüksek su emilimi göz önüne alınarak, kullanılan ince ve iri GKA'ları, doygun yüzey kuru duruma getirmek için önceden 30 dakika 
süreyle suda bekletilmiştir. İri GKA \%0, 50 ve 100 oranlarında doğal agrega ile yerdeğiştirilmiş, ayrıca iri GKA'nın her bir değişim oranı için ince GKA \%0, 25, 50, 75 ve 100 oranlarında doğal agrega ile yerdeğiştirilerek toplam 15 farklı KYB karışımı üretilmiştir. Tüm KYB karışımlarında su/bağlayıcı oranı 0.32 olarak sabit tutulmuş olup, bağlayıcı miktarının \%20'si oranında uçucu kül kullanılmışır. Doygun yüzey kuru durumdaki ince ve iri GKA'ların KYB'nin bazı sertleşmiş özellikleri üzerindeki etkileri araştırılmıştır. Üretilen KYB'lerin sertleşmiş özelliklerini belirlemek için hızlı klor geçirimliliği, kılcal su geçirimliliği ve basınç dayanımı deneyleri yapılmıştır.

\section{MATERYAL VE METOD (MATERIAL AND METHOD)}

\subsection{Malzemeler (Materials)}

Bu çalışmada bağlayıcı malzeme olarak, TS EN 197-1 [22] standardına uygun CEM I 42.5N Portland çimentosu ve Yumurtalık-Sugözü termik santralinden elde edilen ASTM C 618 [23] standardına göre F tipi uçucu kül kullanılmıştır. Çimentonun ve uçucu külün fiziksel özellikleri ve kimyasal analizleri Tablo 1'de verilmiştir.

Tablo 1. Bu araştırmada kullanılan çimento ve uçucu külün kimyasal bileşimi ve fiziksel özellikleri

\begin{tabular}{lll}
\hline Kimyasal analiz (\%) & Portland Çimentosu & Uçucu Kül \\
\hline $\mathrm{CaO}$ & 64.35 & 4.24 \\
$\mathrm{SiO}_{2}$ & 20.08 & 56.2 \\
$\mathrm{Al}_{2} \mathrm{O}_{3}$ & 4.63 & 20.17 \\
$\mathrm{Fe}_{2} \mathrm{O}_{3}$ & 2.84 & 6.69 \\
$\mathrm{MgO}$ & 2.07 & 1.92 \\
$\mathrm{SO}$ & 2.85 & 0.49 \\
$\mathrm{~K}_{2} \mathrm{O}$ & - & 1.89 \\
$\mathrm{Na}$ & - & 0.58 \\
$\mathrm{~K}$ Ozdırma kayb1 & 2,56 & 1.78 \\
\hline Fiziksel özellikler & & \\
\hline Özgül ağırlık & 3.18 & 2.25 \\
İncelik modülü $\left(m^{2} / \mathrm{kg}\right)$ & 318 & 287 \\
\hline Bu & &
\end{tabular}

Bu araştırmada, KYB karışımlarında özgül ağırlığı 1.07 olan polikarboksilik-eter tipi süperakışkanlaştırıcı (SA) kullanılmıştır. İri agrega olarak maksimum $16 \mathrm{~mm}$ boyutundaki nehir çakılı kullanılmıştır. Bu agreganın özgül ağırlık ve su emme değerleri sırasıyla 2.72 ve \% 0.45 'tir. İnce agrega olarak maksimum 5 mm boyutunda nehir kumu ve kırma kalker kullanılmıştır. Özgül ağırlık ve su emme değerleri nehir kumu için $2.66 \mathrm{ve} \% 0.55$, kırma kum için sırasıyla $2.45 \mathrm{ve} \% 0.95$ 'dir. Bu agregaların elek analizi sonuçları Tablo 2 'de verilmiştir.

Tablo 2. Kullanılan doğal agregaların elek analizi sonuçları

\begin{tabular}{lccc}
\hline \multirow{2}{*}{ Elek açıklı̆ğ (mm) } & \multirow{2}{*}{ İri Agrega } & \multicolumn{2}{c}{ İnce Agrega } \\
\cline { 3 - 4 } & & Nehir kumu & Kırma Kum \\
\hline 16 & 100 & 100 & 100 \\
8 & 31.5 & 99.7 & 100 \\
4 & 0.4 & 94.5 & 99.2 \\
2 & 0 & 58.7 & 62.9 \\
1 & 0 & 38.2 & 43.7 \\
0.5 & 0 & 24.9 & 33.9 \\
0.25 & 0 & 5.4 & 22.6 \\
İncelik modülü & 5.68 & 2.79 & 2.38 \\
\hline
\end{tabular}

İnşaat ve yıkıntı atıklarından üretilen GKA'lar beton haricinde ahşap, metal parçaları, tuğla, mermer, alçı, fayans, kiremit ve cam kırıkları gibi malzemeleri içermektedir. Bu malzemelerin GKA içerisindeki varlığı ve miktarındaki değişim, GKA kullanılarak üretilen betonun özelliklerini etkilemektedir. Bu sebeple, sunulan çalışma kapsamında, maksimum 16 mm tane çapına sahip GKA'lar C20 sınıfına ait beton karışımı 
kullanılarak laboratuvar ortamında üretilen 150x150x150 mm boyutuna sahip numunelerin çeneli ve konik kırıcılarda aşamalı olarak kırılmasıyla elde edilmiştir. İlk aşamada beton numuneler Şekil 1(a)'da görülen çeneli kırıcı ile kırılmış ve Şekil 1 (c)'de görülen beton parçalar elde edilmiştir. İkinci aşamada ise bu beton parçalar, Şekil 1(b)'de gösterilen konik kırıcı kullanılarak gerekli boyut ve şekle sahip olacak şekilde ayarlanarak kırılmış ve Şekil 1 (d)'de görülen maksimum tane boyutu 16 mm olan GKA elde edilmiştir.

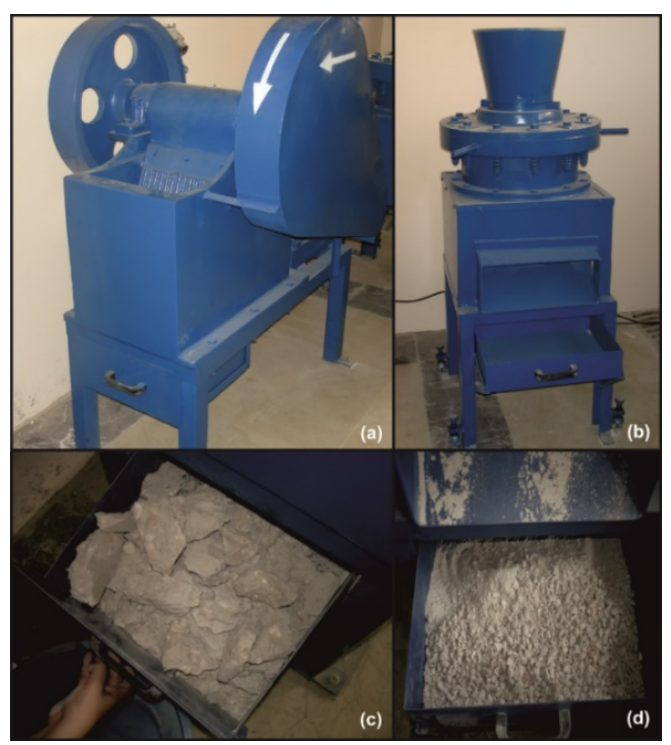

Şekil 1. İki aşamalı kırıcı sistemi ve GKA (a) birincil kırıcı (çeneli kırıcı), (b) ikincil kırıcı (konik kırıcı), (c) çeneli kırıcıdan elde edilen kırılmış betonlar, (d) konik kırıcıdan elde edilen GKA

Elde edilen GKA üzerinde elek analizi yapılarak gradasyon eğrisi elde edilmiştir. GKA, doğal agreganın gradasyon eğrisine uyumlu olmasını sağlamak için 0-4 mm ve 4-16 mm fraksiyonlarına ayrılmıştır. Belirli oranlarda ince ve iri GKA içeren tüm agrega kombinasyonlarının gradasyon eğrileri Şekil 2'de gösterilmektedir. 4-16 mm fraksiyonlara sahip GKA'ların özgül ağırlık ve su emme değerleri sırasıyla 2.4 ve \%7'dir. 0-4 mm'lik fraksiyon için ise bu değerler sırasılyla 2.26 ve \%12.8'dir.

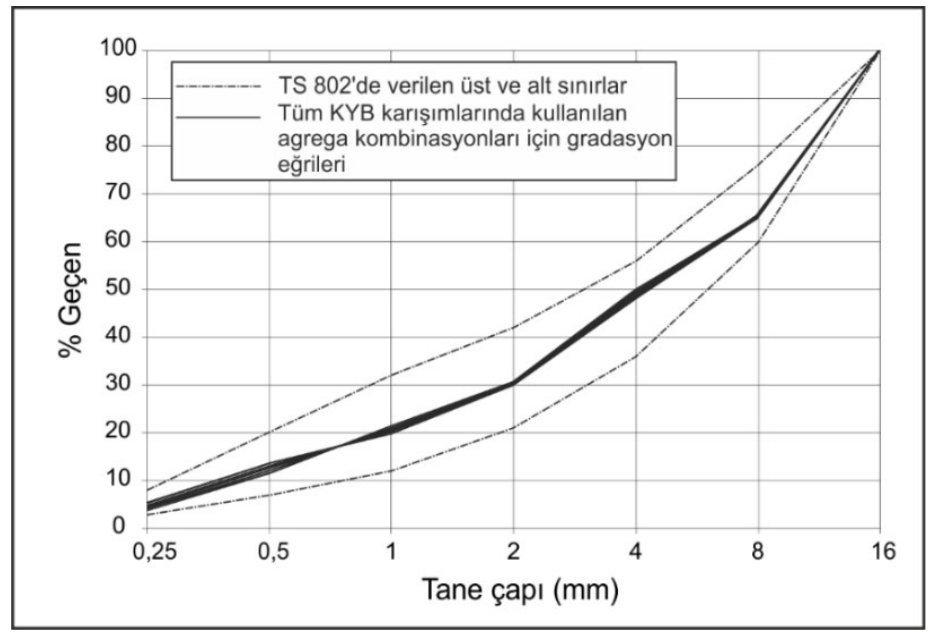

Şekil 2. Agregaların gradasyon ĕgrileri

KYB karışımlarında toplam bağlayıcı miktarı $550 \mathrm{~kg} / \mathrm{m}^{3}$ ve su/bağlayıcı oranı 0.32 olarak sabit tutulmuş olup, tüm karışımlarda uçucu kül bağlayıcı miktarının \%20'si oranında kullanılmıştır. GKA'lar yüksek su emme değerlerine sahip olduğundan dolayı ince ve iri GKA'ları doygun yüzey kuru duruma getirmek için önceden 30 dakika boyunca suda bekletilmiştir. İri GKA \%0, 50 ve 100 oranlarında doğal agrega ile yerdeğiştirilmiş ve iri GKA'nın her bir değişim oranı için ince GKA \%0, 25, 50, 75 ve 100 oranlarında doğal agrega ile yerdeğiştirilerek toplam 15 farklı KYB karışımı tasarlanmış ve karışım oranları Tablo 3'de verilmiştir. 
Tablo 3. KYB karlşım oranları $\left(\mathrm{kg} / \mathrm{m}^{3}\right)$

\begin{tabular}{|c|c|c|c|c|c|c|c|c|c|c|c|}
\hline \multirow[b]{2}{*}{ 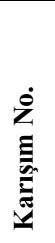 } & \multirow[b]{2}{*}{ Karışım isimleri } & \multirow{2}{*}{ 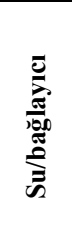 } & \multirow[b]{2}{*}{ : } & \multirow{2}{*}{ 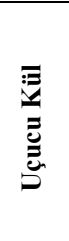 } & \multirow[b]{2}{*}{ Su } & \multirow[b]{2}{*}{ SA } & \multicolumn{3}{|c|}{ Doğal Agrega } & \multicolumn{2}{|c|}{$\begin{array}{c}\text { Geri Kazanılmış } \\
\text { Agrega } \\
\end{array}$} \\
\hline & & & & & & & 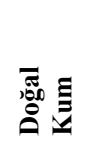 & 音 & 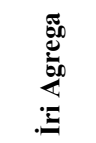 & 蒫 & 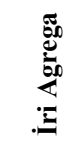 \\
\hline 1 & Kontrol & 0.32 & 440 & 110 & 176 & 6.88 & 555.68 & 238.15 & 832.60 & - & - \\
\hline 2 & GKA\%0İri\%25İnce & 0.32 & 440 & 110 & 176 & 6.88 & 416.76 & 178.61 & 832.60 & 172.95 & - \\
\hline 3 & GKA\%0İri\%50İnce & 0.32 & 440 & 110 & 176 & 6.88 & 277.84 & 119.07 & 832.60 & 345.90 & - \\
\hline 4 & GKA\%0İri\%75İnce & 0.32 & 440 & 110 & 176 & 6.88 & 138.92 & 59.54 & 832.60 & 518.85 & - \\
\hline 5 & GKA\%0İri\%100İnce & 0.32 & 440 & 110 & 176 & 6.88 & - & - & 832.60 & 691.79 & - \\
\hline 6 & GKA\%50İi\%0İnce & 0.32 & 440 & 110 & 176 & 6.88 & 555.68 & 238.15 & 416.30 & - & 367.32 \\
\hline 7 & GKA\%50İri\%25İnce & 0.32 & 440 & 110 & 176 & 6.88 & 416.76 & 178.61 & 416.30 & 172.95 & 367.32 \\
\hline 8 & GKA\%50İri\%50İnce & 0.32 & 440 & 110 & 176 & 6.88 & 277.84 & 119.07 & 416.30 & 345.90 & 367.32 \\
\hline 9 & GKA\%50İri\%75İnce & 0.32 & 440 & 110 & 176 & 6.88 & 138.92 & 59.54 & 416.30 & 518.85 & 367.32 \\
\hline 10 & GKA\%50İri\%100İnce & 0.32 & 440 & 110 & 176 & 6.88 & - & - & 416.30 & 691.79 & 367.32 \\
\hline 11 & GKA\%100İri\%0İnce & 0.32 & 440 & 110 & 176 & 6.88 & 555.68 & 238.15 & - & - & 734.65 \\
\hline 12 & GKA\%100İri\%25İnce & 0.32 & 440 & 110 & 176 & 6.88 & 416.76 & 178.61 & - & 172.95 & 734.65 \\
\hline 13 & GKA\%100İri\%50İnce & 0.32 & 440 & 110 & 176 & 6.88 & 277.84 & 119.07 & - & 345.90 & 734.65 \\
\hline 14 & GKA\%100İri\%75İnce & 0.32 & 440 & 110 & 176 & 6.88 & 138.92 & 59.54 & - & 518.85 & 734.65 \\
\hline 15 & GKA\%100İri\%100İnce & 0.32 & 440 & 110 & 176 & 6.88 & - & - & - & 691.79 & 734.65 \\
\hline
\end{tabular}

Karışımların hazırlanması sürecinde önce doygun yüzey kuru durumdaki GKA'lar çimento ve uçucu kül ile karıştırılmıştır, ardından doğal agrega ilave edilmiştir. Daha sonra, SA içeren su, kademeli olarak karışımlara dahil edilmiştir ve yaklaşık 3 dakika karıştırılmıştır, ardından 1 dakika dinlenmeye bırakılmıştır. Son olarak, karıştırma işlemini tamamlamak için karışım 1-2 dakika daha karıştırılmıştır. Her bir KYB karışımından, basınç dayanımı için altı adet 150x150x150 mm küp numune, hızlı klor geçirimliliği ve kılcal su geçirimliliği deneyleri için sekiz adet 100x200 mm boyutlarında silindir numune üretilmiştir. Beton numuneler dökümden 24 saat sonra kalıptan çıkarılmış ve daha sonra deney zamanına kadar su kürü uygulanmıştır.

\subsection{Yöntem (Method)}

Basınç dayanımı deneyi ASTM C 39 [24] standardına uygun olarak 28. ve 90. günlerde üçer adet numune üzerinde yapılmıştır. Basınç dayanımı değeri test edilen üç numunenin sonuçlarının ortalaması alınarak hesaplanmıştır.

KYB'lerin klor iyon penetrasyonuna karşı direncini belirlemek için ASTM C 1202 [25] standardına uygun olarak hızlı klor geçirimliliği deneyi yapılmıştır. Bu deney 28. ve 90. günlerde $100 \times 200 \mathrm{~mm}$ boyutundaki silindir numunenin ortasından kesilen $50 \mathrm{~mm}$ kalınlığındaki disk numune üzerinde yapılmıştır. Disk numuneler, numunenin bir yüzünün $0.30 \mathrm{~N} \mathrm{NaOH}$ çözeltisi ile ve diğer yüzünün ise $\% 3 \mathrm{NaCl}$ çözeltisi ile temas ettirildiği test hücresine yerleştirilmiştir (Şekil 3). Yüzlere $60.0 \pm 0.1$ V'luk bir doğrudan voltaj uygulanmıştır. Veri kaydedici, beton numuneden geçen akımı 6 saatlik bir süre boyunca kaydetmiştir. Test, 6 saat sonra sona erdiğinde, her beton numune için akıma (amper cinsinden) ve zamana (saniye cinsinden) ilişkin veriler kullanılarak grafik elde edilmiştir ve eğrinin altındaki alan, geçen yükü elde etmek için entegre edilmiştir (coulomb cinsinden).

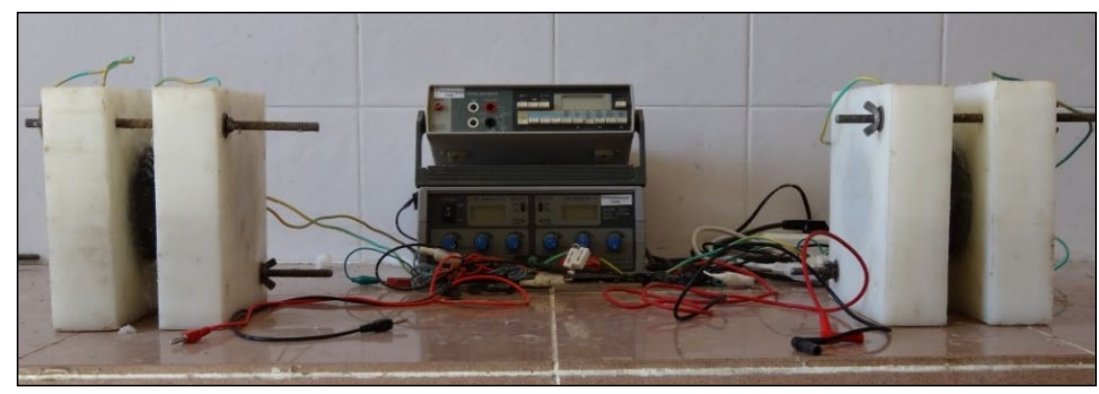

Şekil 3. Hızlı klor geçirimliliği deney düzeneği 
Kılcal su geçirimlilik deneyi, 100x50 mm boyutlarında üç adet silindir disk numune kullanılarak 28. ve 90. günlerde gerçekleştirilmiştir. Numuneler, sabit kütleye ulaşıncaya kadar yaklaşık $50^{\circ} \mathrm{C}^{\prime} \mathrm{de}$ etüvde kurutulmuş ve daha sonra kapalı bir kapta ortam sıcaklığında soğumaya bırakılmıştır. Numunelerin yan yüzeyleri parafin ile kaplanmıştır. Daha sonra sadece numunenin alt yüzeyinden serbest su hareketine izin verilecek şekilde numuneler su ile dolu bir kap içerisine yerleştirilmiştir. Numuneler kap içerisinden belli zaman aralıklarında $(1,4,9,16,25,36,49$ ve 64. dakika) alınarak ağırlıkları tespit edilmiştir. Daha sonra belirtilen her dakika için su emme miktarları hesaplanmış ve bu su emme miktarının, numunenin suya temas eden yüzey alanına oranıyla geçen zamanın karekökü arasında lineer bir ilişki elde edilmiştir. Bu lineer ilişkiden elde edilen doğrunun eğiminden kılcal su emme katsayısı hesaplanmıştır.

\section{BULGULAR VE TARTIŞMA (TEST RESULTS AND DISCUSSIONS)}

Şekil 4'de farklı oranlarda ince ve iri GKA içeren 28 ve 90 günlük KYB numunelerinin basınç dayanımı sonuçlarının değişimi görülmektedir. Genel olarak basınç dayanımı değerleri, sırasıyla 28 ve 90 günlük numuneler için yaklaşık olarak 39-70 ve 44-81 MPa arasında değişmektedir. Şekil 4'de görüldügü gibi, iri ve ince GKA'nın doğal agrega yerine kullanılması KYB'lerin basınç dayanımını önemli ölçüde etkilemektedir. 28 günlük numunelerin basınç dayanımındaki azalma, sırasıyla $\% 50$ ve $\% 100$ iri GKA ikame seviyeleri için yaklaşık olarak \%10 ve \%16 olmuştur. Pereira-de-Oliveira vd. [9], 28 günlük basınç dayanımındaki azalmanın, \%100 iri GKA ikame seviyesi için \%5 olduğunu ifade etmiştir. Grdic vd. [6] de $\% 50$ ve \%100 iri GKA ikame seviyeleri için 28 günlük basınç dayanımı değerlerinin sırasıyla \%3.88 ve $\% 8.55$ oranında azaldığını belirtmiştir.

Şekil 4'de, ince GKA ikame oranı artarken, basınç dayanımı değerlerinde düşüş olduğu açıkça görülmektedir. 28 ve 90 günlük numunelerin basınç dayanımındaki azalma, \% 25-100 ince GKA ikame seviyeleri için, sırasıyla yaklaşık \%12-34 ve \%9-28 arasında değişmektedir. Kou ve Poon [7], 28 ve 90 günlük beton numunelerinin basınç dayanımı değerlerinin, $\% 75$ ve \%100 ince GKA seviyeleri için yaklaşı $\% 10$ azaldığını bildirmiştir. Şekil 4'de ince ve iri GKA ikame seviyelerinin \%100 olması durumunda, 28 ve 90 günlük KYB numunelerinin basınç dayanımı değerlerinin yaklaşık \%44 oranında azaldığg görülebilir.

Yukarıda bahsedilen çalışmaların [6,7,9] sonuçları ve bu yayın kapsamında sunulan basınç dayanımı sonuçları arasındaki farklılıklar, GKA'nın üretildiği betonun basınç dayanımı ve KYB'nin hedeflenen tasarım dayanımı ile ilgili olduğu düşünülmektedir. Zira, bu yayın kapsamında kullanılan GKA $20 \mathrm{MPa}$ basınç dayanımına sahip betondan üretilmiştir. Ancak, önceki çalışmalarda GKA yüksek dayanımlı betondan üretilmiştir. Grdic vd. [6] tarafından kullanılan GKA'ların $37 \mathrm{MPa}$ ve daha yüksek basınç dayanımına sahip betondan üretildiği ifade edilmiştir. 28 günlük KYB numunelerinin hedeflenen tasarım dayanımı dikkate alındığında ise, bu çalışmalarda $[6,7,9]$ hedeflenen basınç dayanım değerleri 45-54 MPa aralığındadır; oysa sunulan araştırmada hedeflenen basınç dayanımı 70 MPa'dır. Bu nedenlerden dolayı, basınç dayanımı sonuçlarında ince ve iri GKA ikame düzeylerine bağlı olarak elde edilen azalma miktarı, önceki çalışmaların $[6,7,9]$ bazılarına göre daha yüksek bir düzeyde olduğu görünmektedir. Dolayısıyla, yeni beton karışımlarını tasarlarken GKA'ların kaynağını bilmek, kullanılan kaynak betonun dayanımı konusunda fikir sahibi olmak önemlidir, çünkü bu çalışmayla görülmektedir ki, GKA ile üretilen betonun dayanımı, kullanılan kaynak betonunun kalitesinden bağımsız değildir. 


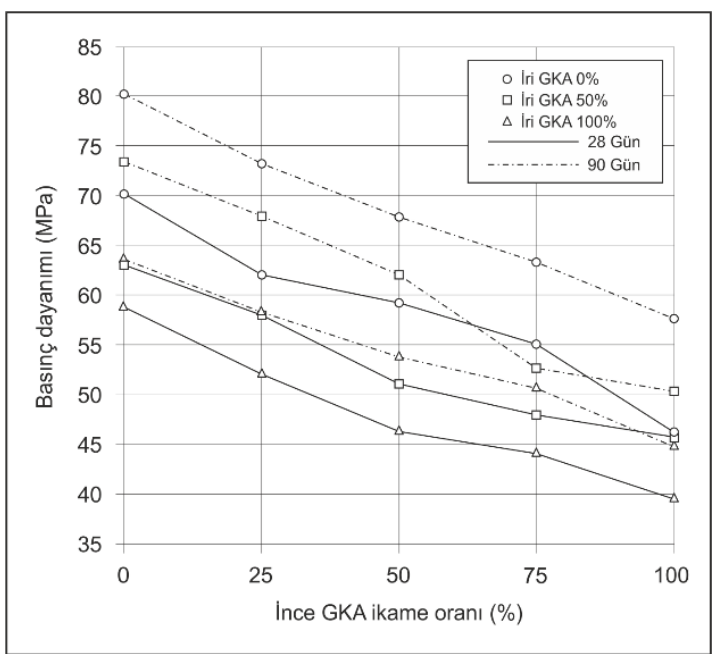

Şekil 4. Kullanılan iri ve ince GKA ikame seviyeleri açısından basınç dayanımının değişimi

İnce ve iri GKA ikame seviyelerine göre, hızlı kor geçirimliliği değerlerinin değişimi Şekil 5'de grafiksel olarak sunulmuştur. Şekil 5'de, ince ve iri GKA ile üretilen KYB'lerin, kontrol betonuna kiyasla, klor geçirimliliğine karşı gösterdiği direncin daha düşük olduğu açıkça görülmektedir. 28 ve 90 günlük kontrol betonu en düşük klor geçirimliliği değerine sahip olup, bu değerler sırasıyla 933 ve 589 Coulombs (C)'tur. \%50-100 iri GKA içeren 28 ve 90 günlük KYB numuneler için ölçülen C değerleri ise, sirasıyla 1.3671.649 ve 1.223-1.358 olarak elde edilmiştir. \%50-100 ince GKA içeren 28 ve 90 günlük KYB numuneleri için, sırasıyla 1.865-2.439 ve 1.204-1.835 C değerleri elde edilmiştir. Bu nedenle, ince GKA kullanımı, özellikle ince GKA ikamesi arttıkça, klor iyonu penetrasyon direncinin azalmasına sebep olduğu ve iri GKA kullanımına göre bu durumun daha etkili olduğu görülmektedir. Şekil 5'de, hem iri GKA hem de ince GKA kullanımının klor geçirimliliğine karşı dirençte belirgin bir düşüş sağladığı anlaşılmaktadır. \%100 GKA kullanılarak üretilen 28 ve 90 günlük KYB numunelerinin hızlı kor geçirimliliği deney sonuçları sırasıyla 3.473 ve 2.839 Coulombs olarak elde edilmiştir.

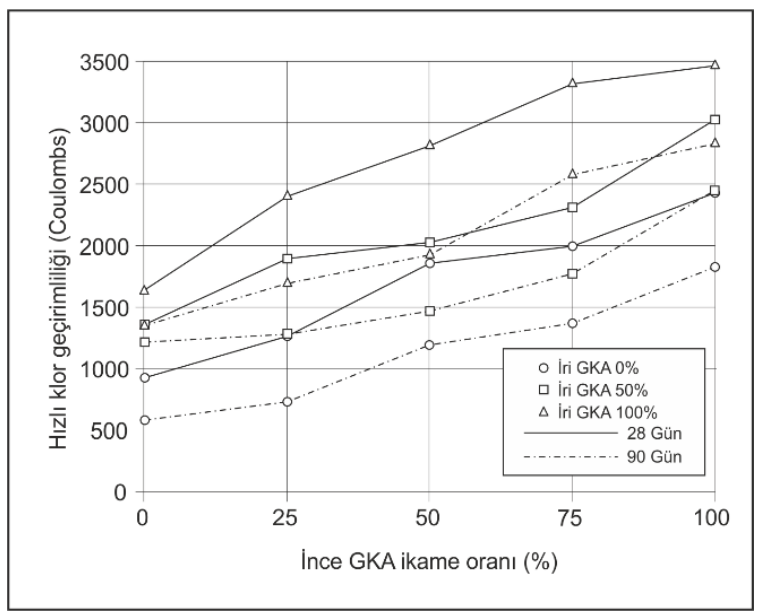

Şekil 5. Kullanılan iri ve ince GKA ikame seviyeleri açısından hızlı klor geçirimliliğinin değişimi

İri ve ince GKA içeren KYB'lerin su emme katsayıları Şekil 6'da sunulmaktadır. Şekil 6'dan görülebileceği gibi, kontrol betonu, her iki kür yaşı için en düşük kılcal su emme katsayısına sahiptir. Bununla birlikte, GKA'nın dahil edilmesi, KYB'lerin kılcal su emme katsayılarını sürekli olarak arttırmaktadır. Şekil 6, GKA oranın artmasıyla kılcal su emme katsayılarının arttığını açıkça göstermektedir. 28 ve 90 günlük KYB numunelerinin kılcal su emme katsayıları, sirasiyla 0.091 ila $0.182 \mathrm{~mm} / \mathrm{dak}^{1 / 2}$ ve 0.086 ila $0.158 \mathrm{~mm} / \mathrm{dak}^{1 / 2}$ arasında değişmektedir. \%50 ve \%100 iri GKA içeren 90 günlük KYB numunelerin kılcal su emme katsayıları değerleri, sırasıyla 0.092 ve $0.104 \mathrm{~mm} / \mathrm{dak}^{1 / 2}$ olmaktadır. Ancak, $\% 50$ ve $\% 100$ ince GKA ikame seviyeleri için bu değerler sırasıyla, 0.112 ve $0.134 \mathrm{~mm} / \mathrm{dak}^{1 / 2}$ olmaktadır. $\% 100$ iri ve ince GKA kullanıldığında ise k1lcal su emme katsayı $0.158 \mathrm{~mm} / \mathrm{dak}^{1 / 2}$ olarak elde edilmiştir. 


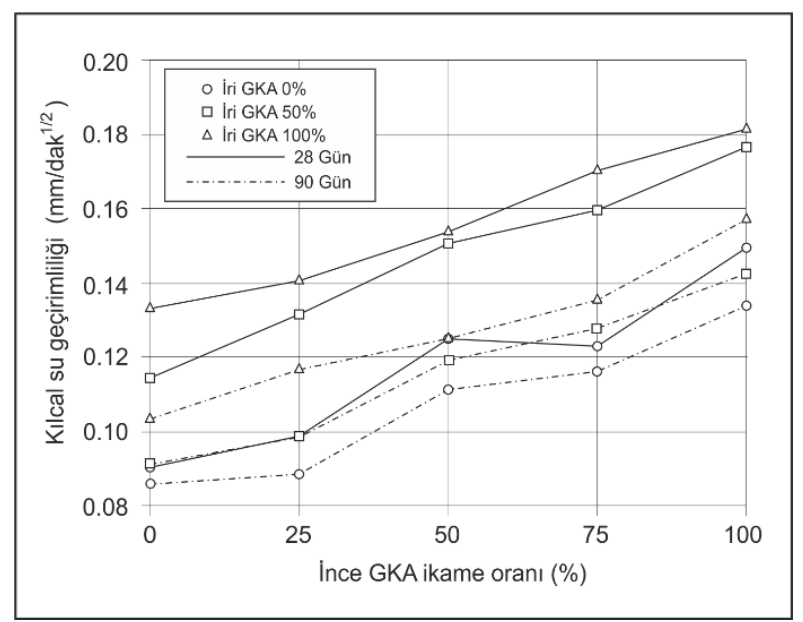

Şekil 6. Kullanılan iri ve ince GKA ikame seviyelerine göre kılcal su geçirimliliğinin değişimi

90 günlük KYB numunelerinden elde edilen basınç dayanımı, hızlı klor geçirimliliği ve kılcal su geçirimliliği deney sonuçları arasındaki ilişkiler Şekil 7(a-c)'de verilmiştir. Şekil 7(a-c) incelendiğinde basınç dayanımı, hızlı klor geçirimliliği ve kılcal su geçirimliliği deney sonuçları arasında oldukça yüksek bir düzeyde korelasyon olduğu görülmektedir.

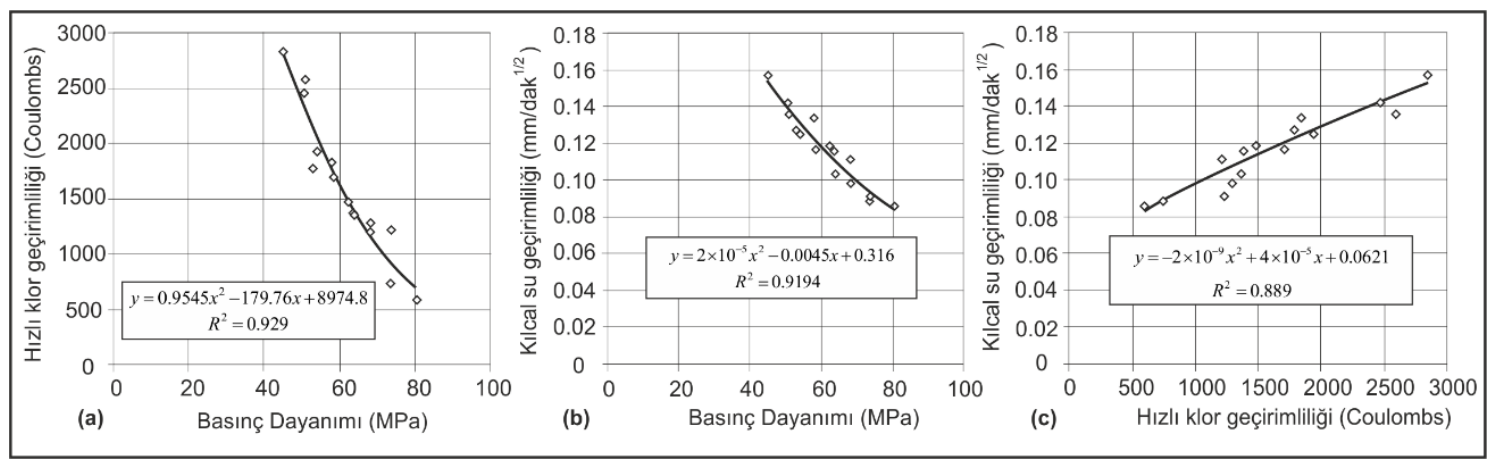

Şekil 7. (a) Basınç dayanımı ile hızlı klor geçirimliliği arasındaki ilişski, (b) basınç dayanımı ile kılcal su geçirimliliği arasındaki ilişki, (c) kılcal su geçirimliliği ile hızlı klor geçirimliliği arasındaki ilişki

GKA'ların su emme kapasitesinin azaltılması ve agrega ile çimento hamuru arasındaki ara yüzey bölgesinin iyileştirilmesi gibi sebeplerden dolayı literatürde GKA'lara uygulanan bazı yüzey iyileştirme yöntemleri bulunmaktadır (Örneğin [11,26-32]). GKA'ların asit çözeltileri içerisinde bekletilmesi yöntemi bunlardan biri olup, GKA üzerindeki eski çimento harcını kaldırmak amacıyla kullanılmaktadır. Bir diğer yöntem ise GKA'ların sodyum silikat solüsyonunda veya çimento-silis dumanı şerbetinde bekletilmesidir ki bu yöntemler GKA'ya yapışmış eski çimento harcını güçlendirmek için kullanılmaktadır. İki aşamalı karıştırma yaklaşımı da bu yüzey iyileştirme yöntemlerinden biri olup uygulamaya yönelik avantajlar içermektedir. Bahsedilen bu yöntemlerin uygulanmasıyla GKA kullanılarak üretilen betonların performanslarında ihtiyaca yönelik iyileşmelerin olabileceği düşünülmektedir.

\section{SONUÇ (CONCLUSION)}

Bu çalışma kapsamında yapılan deneysel araştırmayla aşağıdaki sonuçlara ulaşılmıştır.

1. Doğal agreganın ince ve iri GKA ile ikame düzeyi, KYB'lerin basınç dayanımı sonuçlarında belirgin bir azalmaya neden olmaktadır. 28 günlük basınç dayanımındaki azalma, $\% 100$ iri ve ince GKA ikame seviyeleri için, sırasıyla yaklaşık \%16 ve \%34 olmuştur. Hem ince hem de iri GKA'nın $\% 100$ kullanılması durumunda 28 ve 90 günlük basınç dayanımı değerleri yaklaşık \%44 oranında azalmaktadır.

2. İnce ve iri GKA içeren KYB'ler, kontrol betonununkine kıyasla daha düşük klorür iyonu direnci göstermişlerdir. İnce GKA kullanımı, özellikle ikame oranı arttıkça, klorür iyonu penetrasyon 
direncinin azaltılmasına sebep olduğu ve bu azalışın iri GKA kullanımına göre daha etkili bir düzeyde gerçekleştiği görülmüştür.

3. İri ve ince GKA'nın ikame düzeylerindeki artışa bağlı olarak KYB'lerin kılcal su emme katsayıları, geri kazanılmış agregaların gözenekli mikro yapısı nedeniyle artmaktadır.

4. Yeni beton karışımları tasarlanırken GKA'nın üretildiği betonun dayanımının bilinmesi önemlidir, çünkü üretilecek yeni betonun dayanımı, kullanılan GKA'nın üretildiği betonunun dayanımına büyük oranda bağlıdır.

\section{KAYNAKLAR (REFERENCES)}

[1] M. Sandanayake, G. Zhang, S. Setunge, Estimation of environmental emissions and impacts of building construction - a decision making tool for contractors. Journal of building engineering, 21: (2019) 173-185.

[2] C. T. Marques, B. M. F. Gomes, L. L. Brandli, Consumo de agua e energia emcanteiros de obra: um estudo de caso do diagnostico a açoes visando a sustentabilidade diagnosis to actions aiming at sustainability. Ambiente construído, 17: 4 (2017) 79-90.

[3] L. P. Thives, E., Ghisi, Asphalt mixtures emission and energy consumption: a review. Renewable and sustainable energy reviews 72: (2017) 473-484.

[4] Ö. Öztürk, M. Çelikkol, M. Erkan, Turkish aggregate sector report. Journal of ready mixed concrete, 84: (2007) 52-56. (in Turkish)

[5] V. Corinaldesi, G. Moriconi, The use of recycled aggregates from building demolition in self-compacting concrete. In: Wallevik O, Nielsson I, editors. $3^{\text {rd }}$ International symposium on self-compacting concrete, Iceland, 2003, 251260 .

[6] Z. J. Grdic, G. A. Toplicic-Curcic, I. M. Despotovic, N. S. Ristic, Properties of self-compacting concrete prepared with coarse recycled concrete aggregate. Construction and building materials, $24: 7$ (2010) 1129-1133.

[7] S. C. Kou, C. S. Poon, Properties of self-compacting concrete prepared with coarse and fine recycled concrete aggregates. Cement \& concrete composites, 31: (2009) 622-627.

[8] K. C. Panda, P. K. Bal, Properties of self-compacting concrete using recycled coarse aggregate. Procedia engineering, 51: (2013) 159-164.

[9] L. A. Pereira-de-Oliveira, M. C. S. Nepomuceno, J. P. Castro-Gomes, M. F. C. Vila, Permeability properties of self-compacting concrete with coarse recycled aggregates. Construction and building materials, 51: (2014) 113120.

[10] E. Güneyisi, M. Gesoğlu, Z. Algın, H. Yazıcı, Effect of surface treatment methods on the properties of selfcompacting concrete with recycled aggregates. Construction and building materials, 64: (2014) 172-183.

[11] Z. Algın, Properties of self-compacting concretes prepared with recycled aggregate, Gaziantep Üniversitesi, Fen Bilimleri Enstitüsü, Doktora Tezi, 2015.

[12] E. Güneyisi, M. Gesoğlu, Z Algın, H. Yazıcı, Rheological and fresh properties of self-compacting concretes containing coarse and fine recycled concrete aggregates. Construction and building materials, 113: (2016) 622630 .

[13] I. Gonzalez-Taboada, B. Gonzalez-Fonteboa, F. Martinez-Abella, S. Seara-Paz, Thixotropy and interlayer bond strength of self-compacting recycled concrete. Construction and building materials, 161: (2018) 479-488.

[14] F. Fiol, C. Thomas, C. Muñoz, V. Ortega-López, J. M. Manso, The influence of recycled aggregates from precast elements on the mechanical properties of structural self-compacting concrete. Construction and building materials, 182: (2018) 309-323. 
[15] L. Ferrara, P. Deegan, A. Pattarini, M. Sonebi, S. Taylor, Recycling ceramic waste powder: effects its grain-size distribution on fresh and hardened properties of cement pastes/mortars formulated from SCC mixes. Journal of sustainable cement-based materials, 8: 3 (2019) 145-160.

[16] EFNARC. Specifications and guidelines for self-compacting concrete, English ed. In: European federation for specialist construction chemicals \& concrete systems, 2005.

[17] S. Manzi, C. Mazzotti, M. C. Bignozzi, Self-compacting concrete with recycled concrete aggregate: study of the long-term properties. Construction and building materials, 157: (2017) 582-590.

[18] A. Salesa, J. A. Perez-Benedicto, L. M. Esteban, R. Vicente-Vas, M. Orna-Carmona, Physico-mechanical properties of multi-recycled self-compacting concrete prepared with precast concrete rejects. Construction and building materials, 153: (2017) 364-373.

[19] J. J. Assaad, Influence of recycled aggregates on dynamic/static stability of self-consolidating concrete. Journal of sustainable cement-based materials, $6: 6$ (2017) 345-365.

[20] R. S. Campos, M. P. Barbosa, L. L. Pimentel, G. F. Maciel, Influence of recycled aggregates on rheological and mechanical properties of self-compacting concrete. Revista matéria, 23: 1 (2018).

[21] D. Carro-Lopez, B. Gonzalez-Fonteboa, J. De Brito, F. Martínez-Abella, I. Gonzalez-Taboada, P. Silva, Study of the rheology of self-compacting concrete with fine recycled concrete aggregates. Construction and building materials, 96: (2015) 491-501.

[22] TS EN 197-1. Çimento- Bölüm 1: Genel Çimentolar-Bileşim, Özellikler ve Uygunluk Kriterleri. Türk Standartları Enstitüsü, Ankara, 2012.

[23] ASTM C618. Standard Specification for Coal Fly Ash and Raw or Calcined Natural Pozzolan for Use in Concrete. American society for testing and materials. Annual book of ASTM standards, vol. 04.02, West Conshohocken, PA: ASTM, 2012.

[24] ASTM C39. Standard Test Method for Compressive Strength of Cylindrical Concrete Specimens. American society for testing and materials. Annual book of ASTM standards, vol. 04.02. West Conshohocken, PA: ASTM, 2012.

[25] ASTM C1202. Standard Test Method for Electrical Indication of Concrete's Ability to Resist Chloride Ion Penetration. American society for testing and materials. Annual book of ASTM standards, vol. 04.02. West Conshohocken, PA: ASTM, 2012.

[26] V. W. Y. Tam, C. M. Tam, K. N. Le, Removal of cement mortar remains from recycled aggregate using presoaking approaches. Resources, conservation and recycling, 50: 1 (2007) 82-101.

[27] H. L. Cheng, C. Y. Wang, Improvement of recycled aggregate quality by pre-soaking with water glass. Gypsum cement build, 12: (2004) 12-14 [in Chinese].

[28] J. Li, H. Xiao, Y. Zhou, Influence of coating recycled aggregate surface with pozzolanic powder on properties of recycled aggregate concrete. Construction and building materials, 23: 3 (2009) 1287-1291.

[29] V. W. Y. Tam, X. F. Cao, C. M. Tam, Microstructural analysis of recycled aggregate concrete produced from two-stage mixing approach. Cement concrete research, 35: 6 (2005) 1195-1203.

[30] V. W. Y. Tam, C. M. Tam, Y. Wang, Optimization on proportion for recycled aggregate in concrete using twostage mixing approach. Construction and building materials, 21: 10 (2007) 1928-1939.

[31] V. W. Y. Tam, X. F. Cao, C. M. Tam, Environmental enhancement through use of recycled aggregate concrete in a two-stage mixing approach. Human and ecological risk assessment, 12: 2 (2006) 277-288.

[32] V. W. Y. Tam, C. M. Tam, Diversifying two stage mixing approach (TSMA) for recycled aggregate concrete: TSMAs and TSMAsc. Construction and building materials, 22: 10 (2008) 2068-2077. 